\title{
TENSILE AND FLEXURAL STUDIES ON BANANA AND AMERICANA HYBRID COMPOSITE
}

\author{
DR. K. SRIVIDYA ${ }^{1}$, DR. P. PHANI PRASANTHI ${ }^{2}$, M. RADHA DEVI ${ }^{3}$, G. VAMSI KRISHNA ${ }^{4}$ \\ \& P. ANUROOP \\ ${ }^{1,2}$ Associate Professor, Department of Mechanical Engineering,P V P Siddhartha Institute of Technology, \\ Vijayawada, Andhra Pradesh, India \\ ${ }^{3}$ Assistant Professor, Department of Mechanical Engineering, P V P Siddhartha Institute of Technology,
}

Vijayawada, Andhra Pradesh, India

${ }^{4,5}$ Student, Department of Mechanical Engineering,P V P Siddhartha Institute of Technology,

Vijayawada, Andhra Pradesh, India

KEYWORDS: Natural Fibers; Banana and Americana Hybrid Composites \& Mechanical Properties

Received: Jun 06, 2020; Accepted: Jun 26, 2020; Published: Aug 10, 2020; Paper Id.: IJMPERDAUG202019

\section{INTRODUCTION}

Natural fibers are mostly used in as reinforcements in the composite materials. The main reason for the use of this isto reduce the depletion of the natural resources and degrading environment. Second most thing is that the customers of the materials are opting more towards recyclable materials to be used to create their products. Third reason for increase in such type of usage they are abundantly available when compared with their synthetic fiber counterparts. Some of the natural fibers have high mechanical strength like that of the synthetic fibers. Hybrid composites design has gained a lot of importance in present day as it is possible to tailor the properties of the hybrid composite material to the exact needs of the structure that is under consideration. Most used types of hybrid composites used are inter ply and intra ply hybrid composites. The intra ply composites are the hybrid composites which has two different types of fibers which are embedded inside one matrix to for a lamina. The inter ply hybrid composites are the composites in which the laminate is made up of laminas made up of different fibers and matrices, which means that the ply materials are different within the inter ply hybrid composite.

Banana fibers are one of the most abundantly used fibers which are widely grown and available abundantly. The scientific name of Banana is "Musa Acuminata". Its main contents present in this is cellulose, hemi cellulose, lignin etc., the fiber is light in weight and have high impact strength. It can easily be extracted or purchased and can 
be very easy to handle the fiber. The scientific name of Americana plant is 'Maguey'. It has an application in the field of medicine. Americana(agave) fibers also have high mechanical properties.

The Banana fibers are extracted from the trunk of the banana plant. At First the trunks are taken and then dried by using a banana fiber extraction machine. Once after the extraction of the banana fibers, the fibers should be cleaned in chemical water and then dried or post cured. The Americana fibers are extracted from the leaves of the Agave Americana plant. These fibers are first beaten and then they should soaked in the mud water for several days and then they are again beaten and cleaned with water to remove the unwanted material from the fibers. Again the fibers are socked for several days and then are taken out and finally cleaned and then post cured in sunlight or hot air oven to get the fiber.

[1] R.Badhrinath et.al has taken the sisal/banana fibers hybrid composite and performed different mechanical tests and they found that these banana fiber has high impact strength whereas sisal fiber has the high tensile and high flexural strength. [2] R.Bhupathi et.al have prepared the banana/Glass fiber and the Banana/hemp/Glass fiber hybrid composites and he performed various mechanical tests and he found that banana/Glass fiber composite has high tensile strength and banana/Hemp/Glass fiber composite had high flexural strength. [3] M.Ramesh et.al have performed some experiments on the banana fiber reinforce with epoxy matrix with various fiber volume fractions and he found that the combination of composite with $50 \%$ of fiber volume fraction had high tensile strength. [4] N. Venkateshwaran et. al., had optimized the length and weight ratio of the banana fiber and observed that fiber at $15 \mathrm{~mm}$ length and $16 \%$ of weight fraction, composite had optimized the mechanical properties. [5] N. K. Sharmaet. al., had taken the banana fiber and reinforced with the thermoset matrix and he found out the mechanical properties of the composite. [6] Sutanu Samanta et. al., had manufactured the bamboo/jute fiber reinforced hybrid composite and found this combination exhibits highest tensile strength. [7] A.S. Sigha et. al., had studied the Americana based composites with different fiber weight fractions and found that the $20 \%$ of weight fraction of fiber has best mechanical properties. [8] Vishnu Prasad et. al., had taken the jute fiber composites and conducted various mechanical tests and he proved that Jute fiber can be used an Alternative to the manmade fibers. [9] L. Gandoria et. al., had prepared a model by using the Americana fiber and found that Americana fiber can be used as a reinforcement tin side the composite.K. Srividya[10] studied the strength analysis of banana and americana hybrid composite.

In this paper an intra laminar composite has been made by using banana/americana based hybrid composite fibers reinforced inside epoxy composite at two varying weights of $1.8 \mathrm{~g}$ and $2.1 \mathrm{~g}$ and the mechanical properties of the composite such as longitudinal young modulus and tensile strength and transverse flexural strength, impact strength were found out at different weight ratios.

\section{PROCEDURE}

\section{Materials used}

The fibers were bought fromlocal sources Bindu polymers. Banana and Americana fibers are shown in figure 1 and figure 2.The epoxy was bought from E C mass Pvt. Ltd Hyderabad. MEKP was selected as a catalyst and cobalt was selected as an accelerator which was bought from Bindupolymers. 


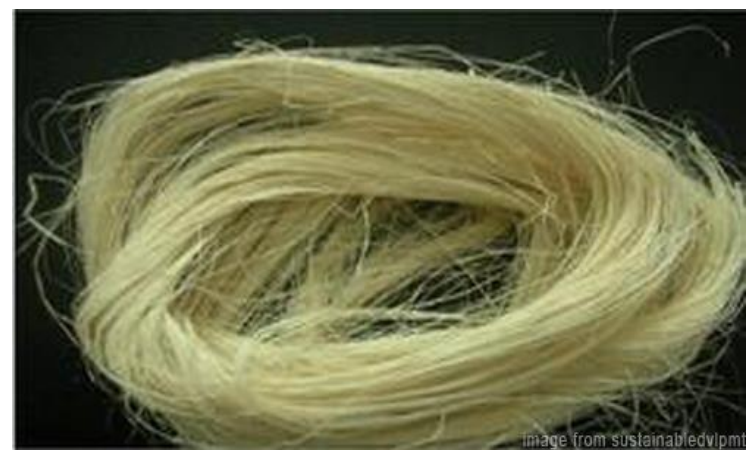

Figure 1: Extracted Banana Fiber.

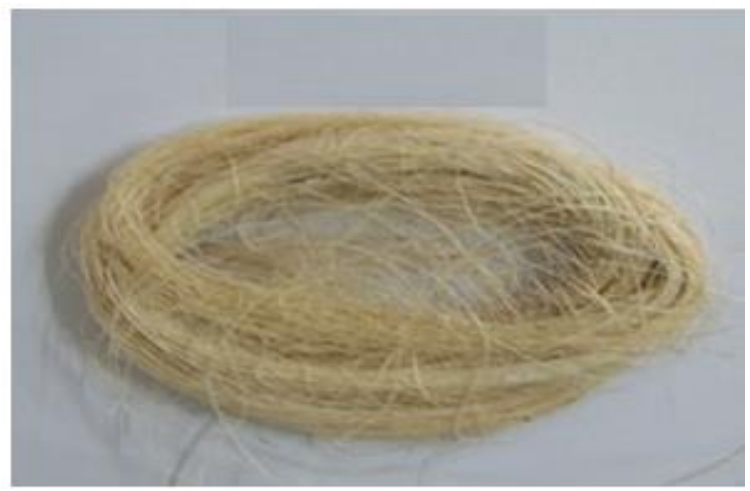

Figure 2: Extracted Americana Fiber.

By using the Hand lay-up procedure the specimens were prepared. Firstly a rubber sheet is taken and is cut in shape of the composite as we required. The fibers are set during a rubber mould and so epoxy is poured in to the mould such the starting layer and also the ending layer are going to be Epoxy and by employing a roller roll on the mould to get rid of the air bubbles. afterward the mould is closed and compression pressure is applied and also the specimens were left to line for about 24-36hrs. After drying the specimens were faraway from the mould very gently so cleaned it to urge a smooth surface finish. After cleaning the specimens, these specimens are again cured for about 3 to 5 hrs under the sun light,because to remove any remaining moisture present within the composite specimen is removed.

\section{Tensile Testing}

The specimens were prepared according to ASTM D638-89 Standard. the quality size of the specimen is $160 \mathrm{~mm} \times 12.5 \mathrm{~mm} \times 3 \mathrm{~mm}$. then the specimens were tested on an electronic tensometer which was supplied by M/S kundale Instruments Pvt. Ltd. From this we obtain the desired stress and strain curves so as to characterize the properties of the specimens. Figure 3 shows the tensile specimens manufactured for the tensile test. a complete of 5 different specimens were prepared at each weight fraction. 


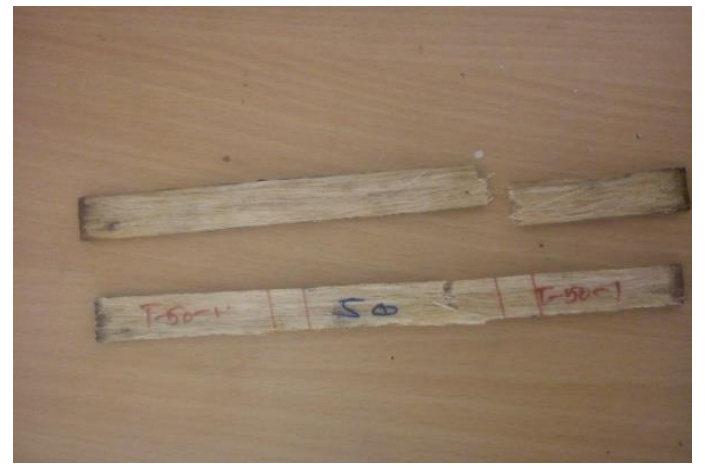

Figure 3: Tensile Test Specimen.

\section{Flexural Test}

The flexural test was performed on the identical electronic tensometer. These Specimens are prepared according to the quality of ASTM D79M $(100 \mathrm{~mm} \times 25 \mathrm{~mm} \times 3 \mathrm{~mm})$. That was wont to perform the tensile test. Figure4 shows the tensile specimens manufactured for the Flexural test.A total of 5 different specimens were created for every weight fraction and for longitudinal combination.

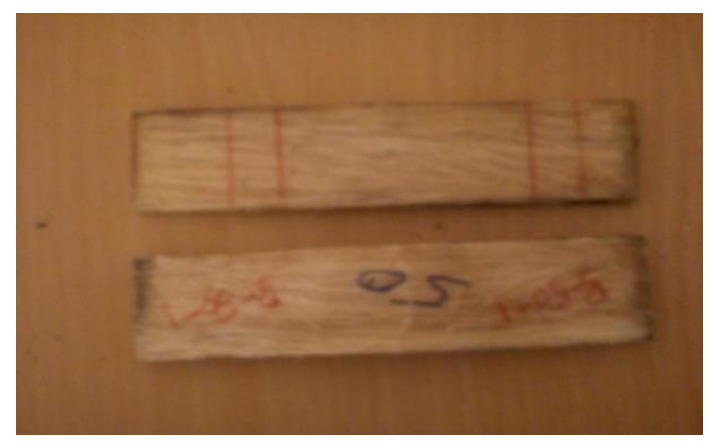

Figure 4: Flexural Test Specimen.

\section{Impact Test}

The impact test specimens were prepared in keeping with the ASTM D256 (63.5mm×10mm×10mm) Standard. The energy absorbed during this impact test are a measure of toughness. Figure 5shows the tensile specimens manufactured for the Impact test. A total of 5 different specimens were created for every weight fraction.

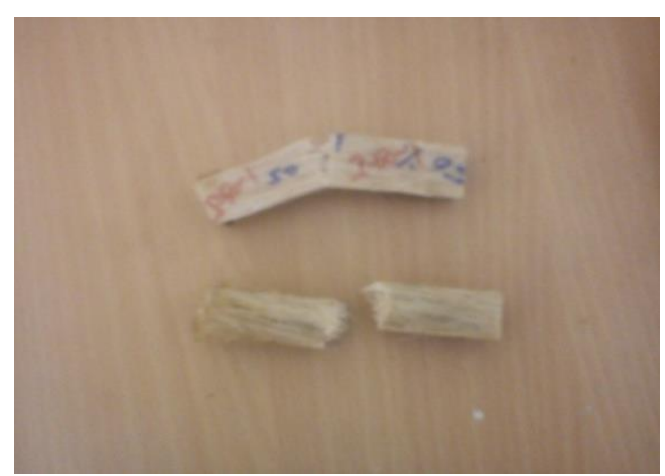

Figure 5: Impact Test Specimen. 


\section{RESULTS \& DISCUSSIONS}

\section{Tensile Test}

From the above tensile tests it is find that the values of the longitudinal young's modulus and transverse young's modulus of the banana/Americana hybridized composite material. It is also find that the longitudinal tensile strength and transverse tensile strength of the hybrid composite. Figure 6 and figure7 shows the variation of the longitudinal young's modulus and transverse young's modulus of the hybrid composites at two different fiber weights embedded into the epoxy. From the figures it is clearly that the longitudinal young's modulus is increasing and also increase was observed in the transverse young's modulus also increase with an increase in the weight ratio of the fibers.

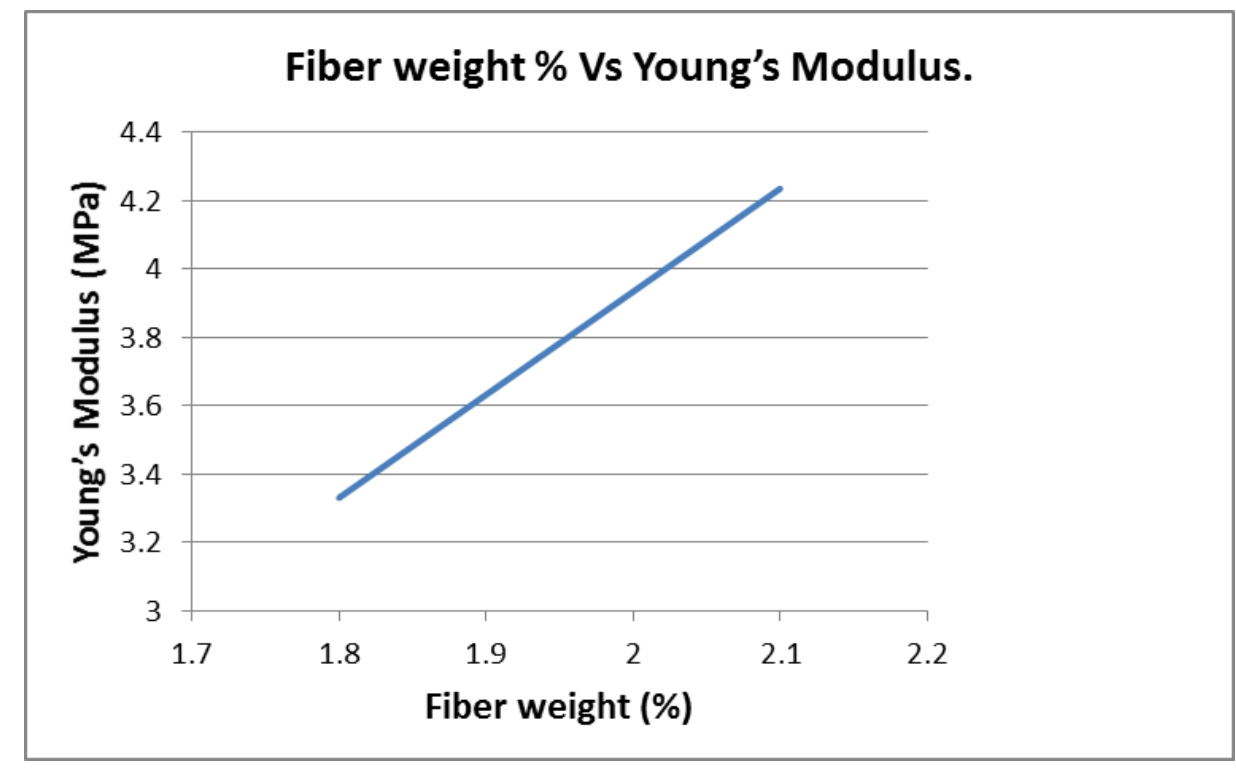

Figure 6: Fiber Weight \% Vs Young's Modulus.

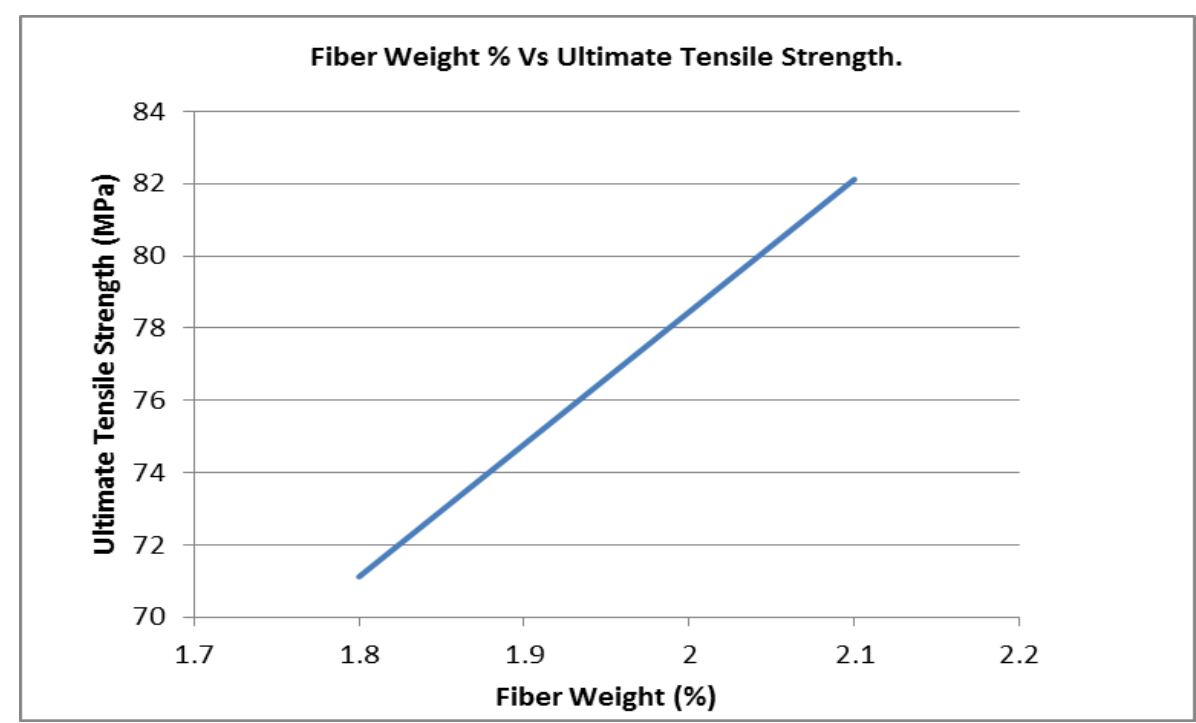

Figure 7: Fiber Weight \% Vs Ultimate Tensile Strength.

Figure 8 and figure9 shows the variation of the longitudinal tensile strength and transverse tensile strength of the hybrid composites at two different fiber weights ratios embedded into the epoxy. From the figures it is clearunderstand that the longitudinal tensile strength increasing and also the increase was observed in transverse tensile strengthwith respect to 
the increase in the fiber weight.

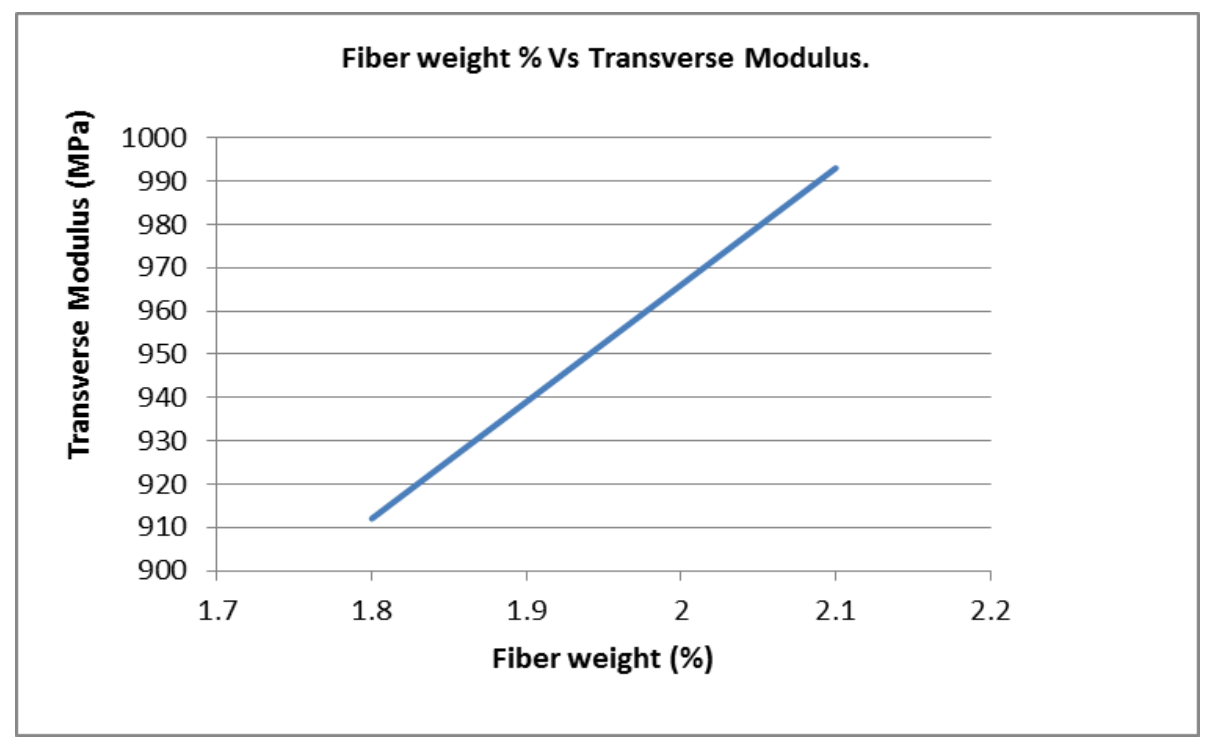

Figure 8: Fiber Weight \% Vs Transverse Modulus.

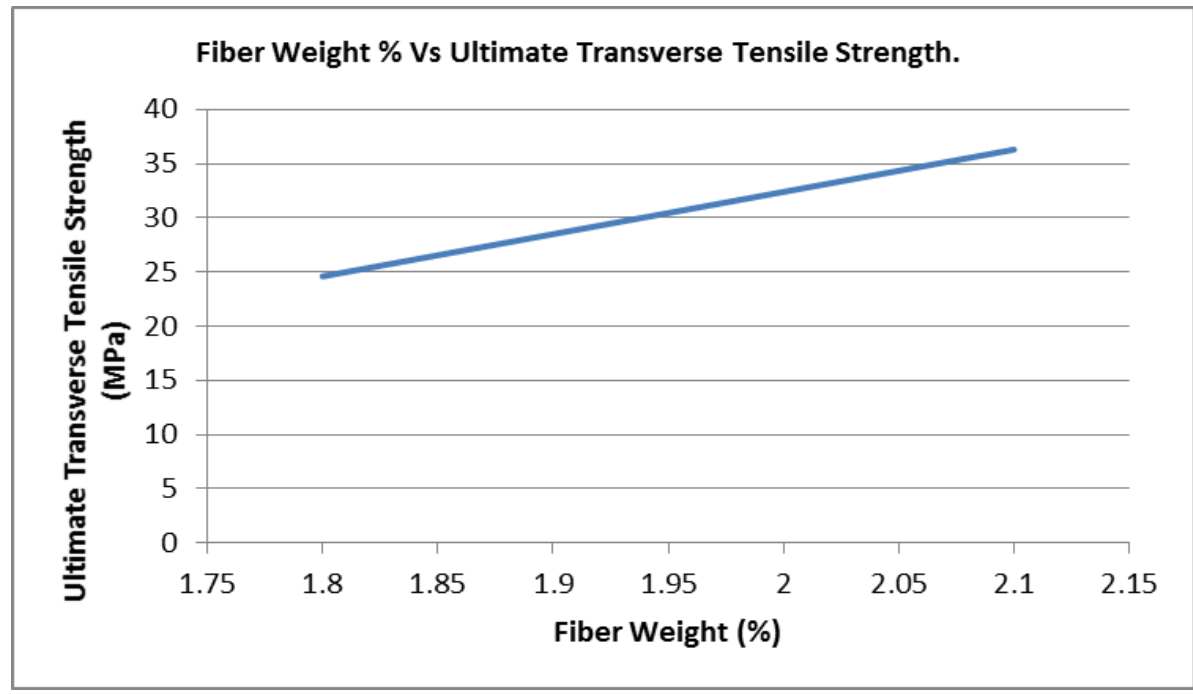

Figure 9: Fiber Weight \% Vs Ultimate Transverse Tensile Strength.

\section{Flexural Test}

From the Flexural tests it is found out that the values of the longitudinal bending modulus of the banana/Americana hybridized composite material. It also found the longitudinal bending strength of the hybrid composite. Figure10 and figure11 shows that how the longitudinal bending modulus of the hybrid composites varies at two different fiber weights ratios embedded into the epoxy. From the figures it is clear understand that the longitudinal bending modulus is increasingwith respect to the increase in the fiber weight. 


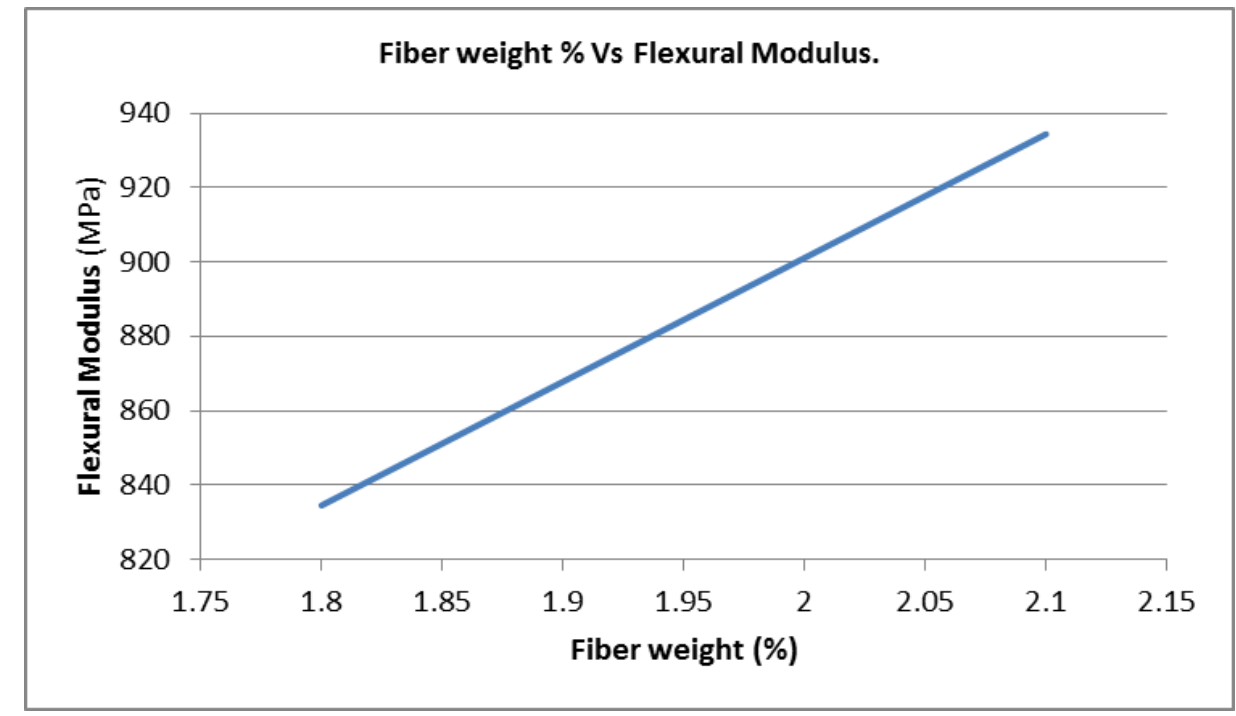

Figure 10: Fiber Weight \% Vs Flexural Modulus.

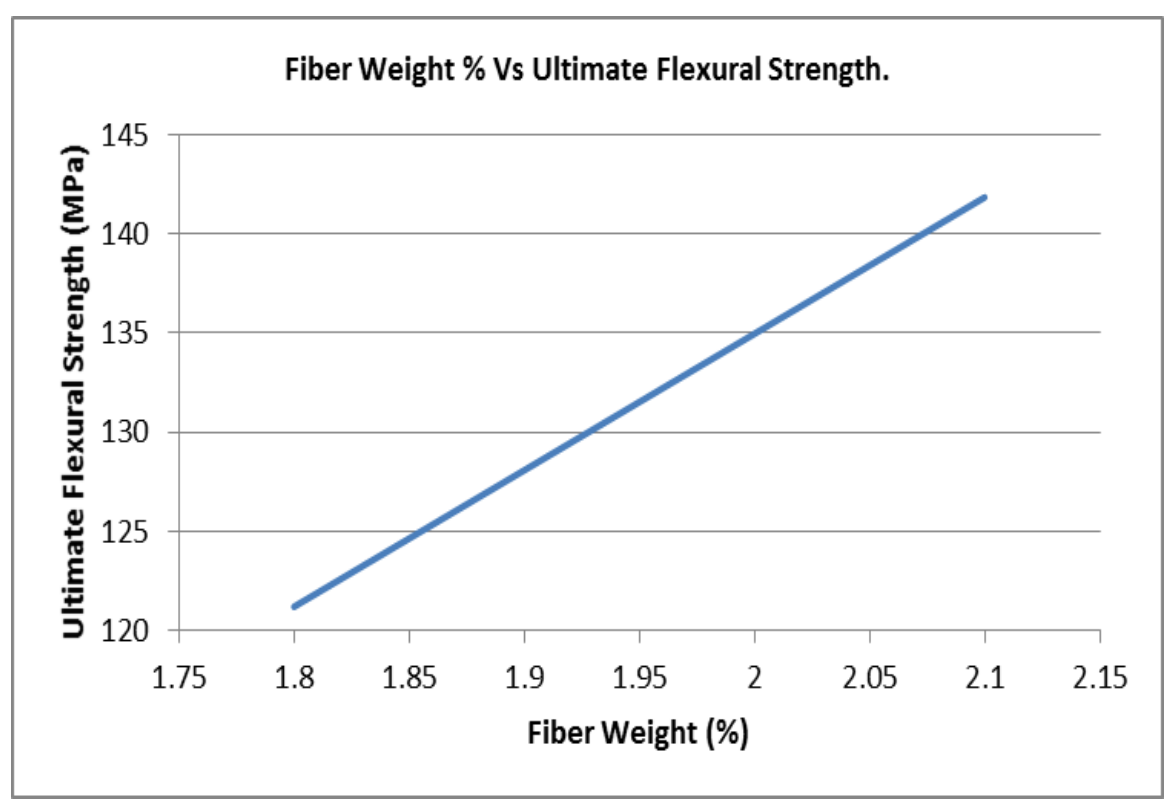

Figure 11: Fiber Weight \% Vs Ultimate Flexural Strength.

\section{Impact Test}

From the impact tests it is found that the values of the impact strength of the banana/Americana based hybridized composite material. Figure12 shows how the impact strength of the hybrid composites varies at two different fiber weights ratios embedded into the epoxy. From the figures it is clearly understand that the tensile strength is increasing with respect to the increase in the fiber weight ratio. 


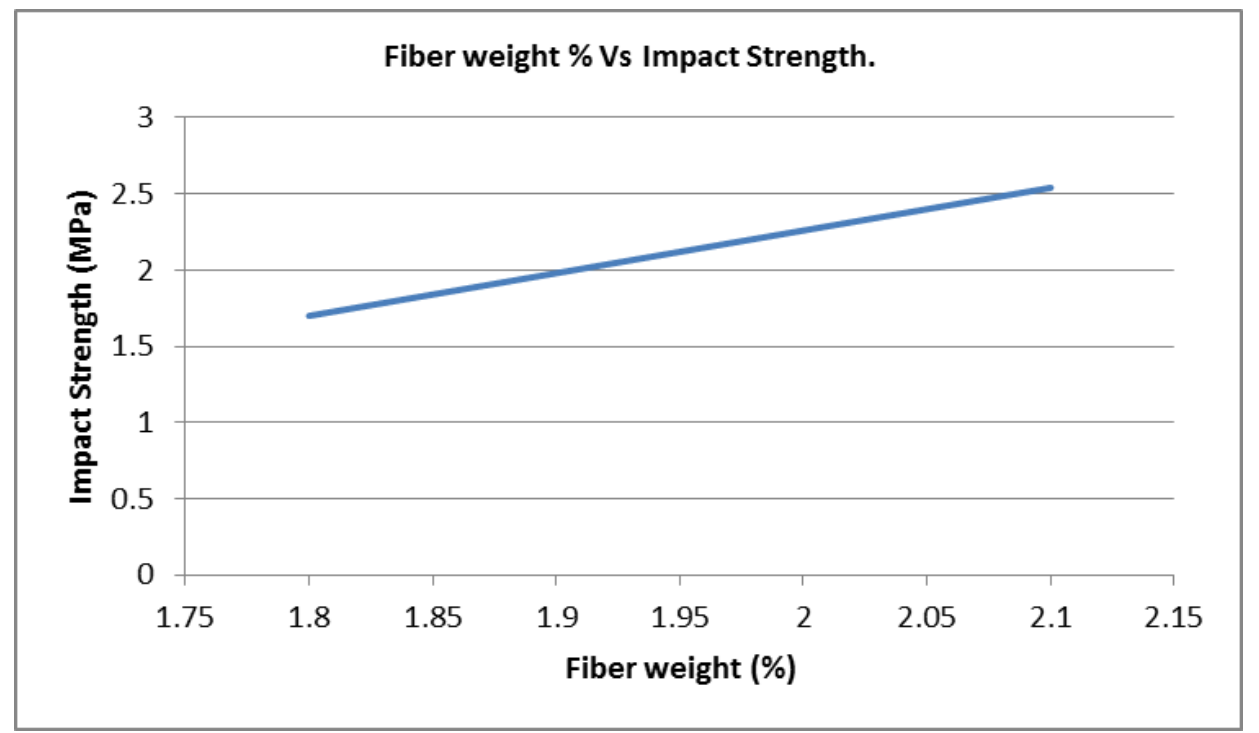

Figure 12: Fiber Weight \% Vs Impact Strength.

\section{CONCLUSIONS}

In this paper an natural hybrid composite has been prepared successfully which have been reinforced inside epoxy composite at two different weights of $1.8 \mathrm{gm}$ and $2.1 \mathrm{gm}$ and the properties such as longitudinal young modulus, tensile strength, transverse flexural strength and impact strength were characterized according with different ASTM standards that are using universally.

From the above it can be concluded that:

- The values of the different mechanical properties such as longitudinal young modulus and tensile strength and transverse flexural strength, impact strength were successfully characterized.

- Americana/Banana hybrid composite can be used as one of the alternative composite material for different types of usage.

- Longitudinal young's modulus and longitudinal tensile strength is increasing with respect to fiber weight.

- Transverse young's modulus and Transverse tensile strength is increasing with respect to fiber weight.

- Longitudinal Flexural modulus and Longitudinal Flexural strength is increasing with respect to fiber weight.

- Impact strength of the composite is increasing with increasing to the fiber weight.

\section{REFERENCES}

1. R. Badrinath and T. Senthilvelan, "Comparative Investigation on Mechanical Properties of Banana and Sisal Reinforced Polymer based Composites," Procedia Mater. Sci., vol. 5, pp. 2263-2272, 2014.

2. R. Bhoopathi, M. Ramesh, and C. Deepa, "Fabrication and property evaluation of banana-hemp-glass fiber reinforced composites," Procedia Eng., vol. 97, pp. 2032-2041, 2014.

3. Anudeep, P., et al. "Experimental Analysis On Treated And Untreated Grass/Carbon Hybrid Composite Structures." International Journal of Applied Engineering Research And Development (2018). 
4. M. Ramesh, T. S. A. Atreya, U. S. Aswin, H. Eashwar, and C. Deepa, "Processing and Mechanical Property Evaluation of Banana Fiber Reinforced Polymer Composites,” Procedia Eng., vol. 97, pp. 563-572, 2014.

5. N. Venkateshwaran, A. ElayaPerumal, and M. S. Jagatheeshwaran, "Effect of fiber length and fiber content on mechanical properties of banana fiber/epoxy composite,” J. Reinf. Plast. Compos., vol. 30, no. 19, pp. 1621-1627, 2011.

6. N. K. Sharma and V. Kumar, "Studies on properties of banana fiber reinforced green composite," J. Reinf. Plast. Compos., no. 00, pp. 1-8, 2012.

7. Santhosh, M. S., et al. "Investigation of mechanical and electrical properties of Kevlar/E-glass and Basalt/E-glass reinforced hybrid composites." International Journal of Mechanical and Production Engineering Research and Development 8.3 (2018): 591-598.

8. S. Samanta, M. Muralidhar, T. J. Singh, and S. Sarkar, "Characterization of Mechanical Properties of Hybrid Bamboo/GFRP and Jute/GFRP Composites, ” in Materials Today: Proceedings, 2015, vol. 2, no. 4-5, pp. 1398-1405.

9. JEEWG, MUHSIN J., ABDAL-KAREEM F. HASSAN, and JAWAD K. ZEBOON. "Experimental and numerical investigation of the dynamic characteristic of laminated composite plate hybrid with steel." Int. J. of General Eng. and Techn.(IJGET) 3 (2014): 1 .

10. A. S. Singha and R. K. Rana, "Preparation and properties of agave fiber-reinforced polystyrene composites," J. Thermoplast. Compos. Mater., 2011.

11. V. Prasad, A. Joy, G. Venkatachalam, S. Narayanan, and S. Rajakumar, "Finite element analysis of jute and banana fibre reinforced hybrid polymer matrix composite and optimization of design parameters using ANOVA technique," in Procedia Engineering, 2014, vol. 97, pp. 1116-1125.

12. Al-Shammari, Mohsin Abdullah, and Muhannad Al-Waily. "Theoretical and numerical vibration investigation study of orthotropic hyper composite plate structure." International Journal of Mechanical \& Mechatronics Engineering IJMMEIJENS 14.06 (2014).

13. L. Ganduri, A. F. Van der Merwe, and S. Matope, "Economic Model for the Production of Spirit, Inulin and Syrup from the Locally Eco-friendly Agave Americana," Procedia CIRP, vol. 28, pp. 173-178, 2015.

14. Vidyasri Khadanga, Dr.K.Srividya, N.Raghuram,Ch.Mohan Sumanth and Sd.Valibabu, "strength analysis of banana and americana hybrid composite," International journal of research and analytical reviews, vol.6,pp.767-772. 
